\title{
Positive affect and resilience: Exploring the role of self-efficacy and self-regulation. A serial mediation model
}

\begin{tabular}{|c|c|}
\hline \multicolumn{2}{|c|}{$\begin{array}{l}\text { Authors: } \\
\text { Daphne Pillay }{ }^{1} \text { (D) } \\
\text { Petrus Nel }{ }^{2} \\
\text { Ebben van } \mathrm{Zyl}^{3}\end{array}$} \\
\hline $\begin{array}{l}\text { Affiliations: } \\
{ }^{1} \text { Department } \\
\text { Resource Man } \\
\text { Faculty of Eco } \\
\text { Management } \\
\text { University of } \\
\text { Pretoria, Sout }\end{array}$ & $\begin{array}{l}\text { f Human } \\
\text { agement, } \\
\text { nomic and } \\
\text { Sciences } \\
\text { retoria, } \\
\text { h Africa }\end{array}$ \\
\hline $\begin{array}{l}{ }^{2} \text { Department } \\
\text { Psychology an } \\
\text { Management, } \\
\text { Management, } \\
\text { Johannesburg } \\
\text { South Africa }\end{array}$ & $\begin{array}{l}\text { f Industrial } \\
\text { d People } \\
\text { School of } \\
\text { University of } \\
\text { Johannesburg, }\end{array}$ \\
\hline $\begin{array}{l}{ }^{3} \text { Department } \\
\text { Psychology, Fac } \\
\text { and Managem } \\
\text { University of } t \\
\text { Bloemfontein, }\end{array}$ & $\begin{array}{l}\text { f Industrial } \\
\text { ulty of Economic } \\
\text { ent Sciences, } \\
\text { ne Free State, } \\
\text { South Africa }\end{array}$ \\
\hline $\begin{array}{l}\text { Correspondin } \\
\text { Daphne Pillay, } \\
\text { daphne.pillay }\end{array}$ & $\begin{array}{l}\text { g author: } \\
\text { @up.ac.za }\end{array}$ \\
\hline $\begin{array}{l}\text { Dates: } \\
\text { Received: } 21 \mathrm{I} \\
\text { Accepted: } 21 \\
\text { Published: } 26\end{array}$ & $\begin{array}{l}\text { May } 2021 \\
\text { Jct. } 2021 \\
\text { Jan. } 2022\end{array}$ \\
\hline $\begin{array}{l}\text { How to cite th } \\
\text { Pillay, D., Nel, } \\
\text { (2022). Positiv } \\
\text { resilience: Exp } \\
\text { of self-efficacy } \\
\text { self-regulation } \\
\text { mediation mo } \\
\text { of Industrial P } \\
\text { Tydskrif vir Be } \\
48(0) \text {, a } 1913 \text {. } \\
\text { org/10.4102/s }\end{array}$ & $\begin{array}{l}\text { is article: } \\
\text { P., \& Van Zyl, E. } \\
\text { e affect and } \\
\text { loring the role } \\
\text { and } \\
\text { A serial } \\
\text { del. SA Journal } \\
\text { sychology/SA } \\
\text { dryfsielkunde, } \\
\text { https://doi. } \\
\text { ajip.v48i0.1913 }\end{array}$ \\
\hline $\begin{array}{l}\text { Copyright: } \\
\text { (C) 2022. The } \\
\text { Licensee: AOS } \\
\text { is licensed un } \\
\text { Creative Comr } \\
\text { Attribution Lic }\end{array}$ & $\begin{array}{l}\text { uthors. } \\
\text { IS. This work } \\
\text { ler the } \\
\text { nons } \\
\text { ense. }\end{array}$ \\
\hline $\begin{array}{l}\text { Read online: } \\
\text { 口is: }\end{array}$ & $\begin{array}{l}\text { Scan this QR } \\
\text { code with your } \\
\text { smart phone or } \\
\text { mobile device } \\
\text { to read online. }\end{array}$ \\
\hline
\end{tabular}

Orientation: Resilience has become an invaluable asset for female leaders in higher education given the numerous barriers they have to overcome. Despite this, leadership development programmes tend to overlook the importance of resilience enhancing factors when offering support interventions for female leaders.

Research purpose: This study explores the role of psychological resources such as positive affect, self-efficacy and self-regulation and the processes between them that explain resilience.

Motivation for the study: Understanding how psychological resources can work independently and through each other to influence resilience, can prove beneficial for higher education institutions. This information can be used to design female leadership support programmes that enhance the appropriate psychological resources, which may assist with increasing resilience.

Research approach/design and method: This study employed a cross-sectional survey design with a non-probability sample of female leaders $(n=255)$ across multiple higher education institutions in South Africa. Mplus was used to determine the goodness-of-fit associated with the different constructs. Statistical Package for the Social Sciences (SPSS) version 27 and PROCESS macro by Hayes were used to conduct a series of statistical tests, including serial mediation analysis.

Main findings: Although the relationship between positive affect and resilience was mediated by self-efficacy and self-regulation (individually and in serial), positive affect had a positive association with resilience independent of the three indirect effects.

Practical/managerial implications: Higher education institutions can strengthen the resilience of female leaders through interventions that utilise positive affect, self-efficacy and selfregulation.

Contribution/value-addition: This study contributes towards research on the role of psychological resources in the context of female leadership and aims to explain the processes that may influence resilience.

Keywords: positive affect; self-efficacy; self-regulation; resilience; serial mediation.

\section{Introduction}

Whilst women comprise over $50 \%$ of the higher education labour force in South Africa, they are still severely under-represented in leadership positions (Kele \& Pietersen, 2015; Pillay, 2020). The lack of women leaders indicates a business case, a wastage of resources, as well as a case for inequities in processes and practices within higher education (Morley, 2013). The underrepresentation of women leaders in higher education has resulted in the expertise and skills of a significant part of the workforce are being under-utilised, which negatively affects the performance of these institutions (Morley, 2013). Research on female leadership in the higher education sector (Kele \& Petersen, 2015; Linden, 2012; Morley, 2013; Pillay, 2020) has established that a key factor contributing to the lack of female leaders in higher education includes numerous barriers women face. These barriers include but are not limited to women not having a leadership identity, lack of opportunity and support in the higher education sector, discouragement and sabotage and the different expectations for men and women leaders (Hannum, Muhly, ShockleyZalabak, \& White, 2015). Whilst the significance of these barriers has been acknowledged, researchers (Reed \& Blaine, 2015; Weatherspoon-Robinson, 2013) argue that the few women, who 
are able to successfully overcome these barriers to achieve leadership positions, possess the psychological strength of resilience and this sets them apart from women who succumb to these barriers.

Whilst the concept of resilience pervades us in everyday life, its role in the workplace is fundamental in understanding how organisations and more specifically their female leaders effectively handle adversity, a concept that has become even more important given the current disruptive and adverse work environment (Hartmann, Weiss, Newman, \& Hoegl, 2020). In addition to dealing with the barriers to career progression which their male counterparts do not have, female leaders in South Africa have to lead during the global pandemic and civil and political unrest in the country, which makes resilience an increasingly important resource to have. Given the importance of resilience for female leaders, researchers (Forbes-Genade \& Van Niekerk, 2019; Pillay, 2020) have emphasised the need to investigate different factors that can enhance resilience for women in the workplace within the context of leadership. Authors argue that the existing literature on protective resilience factors and their underlying mechanisms cannot simply be transferred to the leadership context as the effects of those factors depend on the context (Foerster \& Duchek, 2017). This suggests that the psychological resources that are effective in enhancing the resilience levels of the general working population might not yield the same results for the resilience of female leaders.

Whilst research in the field of female leadership has attempted to explore how resilience is enhanced, a large number of studies have adopted a socio-ecological approach in investigating resilience. These studies focus on external factors that influence resilience processes, such as organisational climate (Manomenidis, Panagopoulou, \& Montgomery, 2019), work experiences (Southwick, Martini, Charney, \& Southwick, 2017) and social and professional support (Cusack et al., 2016). In addition, studies that have focused on internal factors of resilience tend to concentrate on direct relationships without any attempt to understand the processes through which internal factors can indirectly explain resilience (Duchek, 2018). As a result, authors in the field of resilience (Gray \& Jones, 2018; Tau, Du Plessis, Koen, \& Ellis, 2018) argue for the importance of studies that investigate the internal processes and mechanisms, that is, the processes through which emotions, behaviour and cognitions can work interdependently to explain resilience processes for female leaders. Hence, there is a call for studies that aim to shed light on how internal aspects of functioning such as affective (processes related to managing and regulating emotions), behavioural (processes related to understanding and modifying behaviours) and cognitive strategies (processes related to understanding and controlling thoughts and thinking patterns) all associate with each other to explain the resilience process for female leaders (Duchek, 2018). This study answers this call by investigating affective (positive affect), behavioural (self-regulation) and cognitive (self-efficacy) factors and how they work both directly and indirectly to explain resilience for female leaders.

\section{Research purpose and objective}

This study is confirmatory in nature and aims to confirm the direct and indirect relationships between positive affect, selfefficacy, self-regulation and resilience. According to Park, Peterson and Seligman (2004), psychological resources refer to positive personal attributes that manifest itself through cognition, emotion and behaviour and exist in varying degrees for each individual. Whilst these psychological resources are entities that hold value in their own right, they possess the ability to significantly influence each other through direct and indirect ways and work to collectively bring about positive outcomes such as resilience (Hobfoll, 2002). These psychological resources are results of internal processes, that is, affective, behavioural and cognitive functioning (Tyng, Amin, Saad, \& Malik, 2017). Understanding these processes and the way they associate with each other to explain resilience, will assist higher education institutions in creating strategies to help enhance resilience for female leaders. Within the context of this study, positive affect is seen as an affective resource, self-regulation is seen as a behavioural resource and self-efficacy is seen as a cognitive resource. Thus, the objective of the current study is to investigate the direct and indirect relationship between positive affect and resilience whilst modelling a process through which positive affect associates with self-efficacy, which in turn associates with self-regulation, which in turn associates with resilience. This can be summarised as the process in which affect (positive affect) associates with cognition (self-efficacy) which associates with behaviour (self-regulation) which ultimately explains resilience. In essence, there are two primary contributions of this study, that is, the development of a theoretical model depicting how certain psychological resources (positive affect, self-efficacy and self-regulation) relate to resilience and the testing of the above model, by investigating the direct and indirect effects.

In the subsequent section, a literature review focusing on positive affect, self-efficacy, self-regulation and resilience is provided.

\section{Literature review and theoretical background Direct relationship between positive affect and resilience}

Positive affect is defined as an individual's general disposition or mood state with regard to the experience of positive emotions across situations and is usually more enduring than emotion (Watson \& Clark, 1992). Individuals who experience higher levels of positive affect are characterised by high levels of vitality, high alertness and pleasurable engagement, whereas those who experience lower levels of positive affect or negative affect are characterised by sadness and lethargy (Sagone \& Indiana, 2017). The role of positive affect in predicting resilience can be explained by the broaden-and-build theory of positive emotions (Tugade \& Fredrickson, 2004). According to this theory, the experience of positive affect and emotion serves to broaden individual's 
momentary thought-action repertoires. Whilst negative affect is linked to responses that narrow thoughts and actions, positive affect is linked to responses that broaden thoughts and action (Fredrickson, 2008). These broadened thoughts and actions are particularly rare, inventive and flexible and are expected to increase the probability of the individual remaining resilient during adverse conditions (Fredrickson, 2001). The concept of enhanced positive affect resulting in positive outcomes is consistent with the hedonic perspective of well-being (Ryan \& Deci, 2001), which maintains that maximising positive experiences or affect is likely to result in increased positive aspects of well-being including resilience. As a result, the following hypothesis is proposed:

H1: Positive affect is positively associated with levels of resilience

\section{Indirect relationships between positive affect, self-efficacy, self-regulation and resilience}

\section{Positive affect to self-efficacy to resilience}

Luszczynska, Scholz and Schwarzer (2005) define generalised self-efficacy as the belief in one's ability to cope with a broad range of stressful or challenging demands. These self-efficacy beliefs inform how people feel, reason and behave, ultimately determining whether one is able to persevere through difficult situations. Within the context of the current study, self-efficacy can be viewed as a generalisation across various domains of functioning, that is, affective, behavioural and cognitive, in which women leaders judge how efficacious they are. Given the dynamic nature of leadership and numerous barriers and obstacles women leaders face in their career progression, generalised self-efficacy assists in explaining a broader range of human behaviours and coping outcomes when the context is constantly changing.

The link between positive affect, self-efficacy and resilience can be explained by considering the relationship between affect and cognition. Cognitive theorists, Tyng et al. (2017) argue that emotion has a considerable influence on cognitive processes such as awareness, beliefs, attention and perceptive capacities. This assumption is supported by the broadenand-build theory of positive emotions (Tugade \& Fredrickson, 2004), which asserts that the experience of positive affect (e.g. energy, pride and enthusiasm) significantly influences and expands cognitive and behavioural repertoires which leads to adaptive outcomes such as resilience. According to Park, Kim, Kwon and Lee (2018), positive affect increases the range of thoughts and actions that become available to an individual during stressful times. These broadened thoughts and actions are valuable for making positive judgments about one's own abilities (self-efficacy) in dealing with various tasks across various domains of life. When an individual experiences a state of positive emotion, he or she is able to take positive action, which strengthens his or her belief in the ability to successfully deal with barriers or challenges and bounce back from setbacks (i.e. resilience). This assumption is consistent with the findings of Haase, Poulin and Heckhausen (2012) who reported that in their longitudinal study, participants believed that they had elevated control and motivation over-achieving their goals and dealing with stressors when they experienced positive affect. This suggests that maintaining a positive affect is related to one's general belief in one's abilities, which in turn is related to resilience. As a result, the following hypothesis is proposed:

H2. Self-efficacy mediates the relationship between positive affect and resilience.

\section{Positive affect to self-regulation to resilience}

According to Fredrickson (2001), the broadened mindset that often accompanies positive affect, carries enduring adaptive benefits for the individual because broadening builds enduring psychological resources such as self-regulation. The personal resources accrued during these positive states are durable. Tugade and Fredrickson (2004) assert that because the ability to self-regulate will outlast the experience of positive emotions, the individuals are able to draw on their ability to regulate emotions, thoughts and behaviours at a later stage and in different emotional states, which allows for a resilient response to threats or challenges. Tice, Baumeister, Shmueli and Muraven (2007) provide compelling evidence, which indicates that because of its energising effect, positive affect replenishes a depleted self-regulatory system by encouraging creativity, which assists in overriding habit, routine and other automatic responses. The authors go on to add that the capacity of the self to exercise control over and manage behaviour, choices and other acts of desire is crucial, however, this requires significant emotional, cognitive and behavioural resources, which is costly and can sometimes deplete the individual's energy. Positive affect has the ability to restore resources and the capacity to exert control over the self by broadening the thought and action responses and restoring levels of self-regulatory ability (Tice et al., 2007). By regulating behavioural responses during setbacks and adversity, self-regulation allows the individual to display resiliency. As a result, the following hypothesis is proposed:

H3. Self-regulation mediates the relationship between positive affect and resilience.

\section{Positive affect to self-efficacy to self-regulation to resilience}

Marsh and Craven (2006) state that self-efficacy and selfregulation are self-related processes that drive human potential and functioning through interaction with each other. These self-related processes occur within cognitive and behavioural domains of functioning and are greatly influenced by individual factors such as emotional states. In assessing the sources of self-efficacy, Bandura (1982) asserts that emotional states play a significant role in determining the level of self-efficacy one approaches challenges with. According to Akthar (2008), the affective or mood state that one is in will influence how self-efficacy is judged. Positive mood states or positive affect will significantly boost confidence in one's skills and increase self-efficacy beliefs, whereas negative mood states will decrease motivation and belief in the ability to accomplish a range of tasks. Bandura (1994) argues that the link between emotional states and selfefficacy beliefs is supported by research, which indicates that 
individuals who view their emotional responses to a situation as a positive and motivating factor for performance have a well-established sense of self-efficacy.

According to the social cognitive theory of self-regulation (Bandura, 1991), it is this well-established sense of selfefficacy that in turn increases one's ability to self-regulate, ultimately fostering resilience. Bandura (1991) states that self-efficacy plays a dominant role in whether or not one can display personal management (i.e. the ability to regulate aspects of the self). This is because self-efficacy beliefs act as a set of proximal determinants for human functioning which include influencing the choices one makes, their aspirations, the level of effort exerted in a specific situation and more related to the current study, it influences the extent of perseverance in the face of difficulties and setbacks (Bandura, 1991). Additionally, the self-efficacy mechanism can significantly determine whether one's thought patterns are self-impeding or self-aiding which in turn affects how the individual regulates behaviours and thoughts to cope with taxing environmental demands, determining whether one is resilient in stressful situations. This argument indicates that maintaining a positive affect is significantly related to one's self-efficacy belief, which, in turn, is related to the ability to regulate behavioural and emotional responses during times of threat, ultimately explaining levels of resilience. According to Charalambous, Giannakopoulou, Bozas and Paikousis (2019), this type of indirect relationship between variables is referred to as serial mediation, which hypothesises a causal chain linking of mediators (self-efficacy and self-regulation), with a specified direction flow. This study assumes that positive affect is positively related to self-efficacy, which, in turn, is related to self-regulation, which explains resilience. Thus, self-efficacy and self-regulation (in serial) will mediate the relationship between positive affect and resilience. As a result, the following hypothesis is proposed:

H4: There is a serial mediation effect of self-efficacy and selfregulation in the relationship between positive affect and resilience.

\section{Method}

\section{Research approach}

Considering that the primary aim of the study was to investigate the direct and indirect relationships between positive affect, self-efficacy, self-regulation and resilience, an approach that allows for the testing of significant effects and links between variables was adopted. Using a quantitative cross-sectional design, a sample of female leaders in higher education institutions in South Africa was surveyed.

\section{Research participants}

The population included all female employees both academic and professional administrative staff who were identified as leaders across South African universities. The criteria for the selection of female academic leaders in higher education were posts, including senior lecturers, professors and deputy heads of departments and above, that is, deputy head of the department; heads of departments, programme directors, deans of faculty, vice-rectors, vice-chancellors and chancellors. Identifying leadership positions in professional service roles was more complex as the various institutions have different titles for each role. Using the literature on leadership (Van Niekerk, 2005) in the South African context as a benchmark, leaders in professional services were identified as employees who identify with, but not limited to, the following roles and responsibilities: providing input for departmental and organisational planning, setting goals for other employees within the departments or organisations, planning and co-ordinating administrative procedures and systems and devising ways to streamline processes and coaching and mentoring other employees.

Participants were selected using a non-probability purposive sampling method and the final sample consisted of 255 female leaders. Using a survey, respondents were asked to provide demographic information (i.e. age, marital status, education level, years of experience in leadership roles and type of position held).

The demographic variable of age consisted of four categories with the modal value (39.2\%) of respondents falling within the $45-54$-year-old age group, whilst $27.5 \%$ of the sample fell within the 55 years and above category, which was the second highest age group. More than half (61.6\%) of the sample indicated that they were married and $55.3 \%$ of respondents indicated that they possessed a $\mathrm{PhD}$ degree. These high educational levels were anticipated considering that most leadership roles in higher education institutions require $\mathrm{PhD}$ degrees. With regard to the category of employment, $55.7 \%$ of the respondents fell within the academic staff category whilst $40.8 \%$ of the respondents indicated that they worked under the professional services category. Nine respondents failed to indicate which employment category they belonged to. The discrepancy between the number of respondents in academic and professional staff roles was expected as higher education institutions' main form of service is academic in nature. With regard to years of experience, $35.3 \%$ of respondents had more than 10 years of experience.

\section{Measuring instruments}

In addition to the demographic questions, the survey also included items to measure respondents' levels of positive affect, self-efficacy, self-regulation and resilience.

Resilience was measured using the 14-item resilience scale (RS-14) which is a revised version of the original 25-item resilience scale (Wagnild \& Young, 1993). The RS-14 (Wagnild \& Young, 2009) was developed because of the need for shorter instruments in an attempt to reduce participant burden and increase responses. A unidimensional factor structure is suggested (Wagnild \& Young, 2009). Scores on RS-14 range from 1 (strongly disagree) to 7 (strongly agree). An example of an item from RS-14 includes 'I can usually find something to laugh about'. 
Positive affect was measured using the Positive and Negative Affectivity Schedule (PANAS) developed by Watson, Tellegen and Clark (1988). For the purpose of this article, only the positive affectivity schedule was considered. The positivity affect schedule is a 10-item, 5-point Likert-type scale with options ranging from 1 (very slightly or not at all) to 5 (extremely). Participants were asked to rate the extent to which they experience the different emotions which include 'excited' and 'proud', to mention a few.

Self-efficacy was measured by the general self-efficacy scale (GSES) developed by Schwarzer and Jerusalem (1995). The 10-item scale was designed to measure a general sense of perceived self-efficacy and can be interpreted as a unidimensional construct (Schwarzer \& Jerusalem, 1995). Scores on the GSES range from 1 (not true at all) to 4 (exactly true) (Marais, 1997). An example of an item from the GSES is 'I can remain calm when facing difficulties because I can rely on my coping abilities'.

The Short Self-Regulation Questionnaire (SSRQ) developed by Carey, Neal and Collins (2004) was used to measure self-regulation. The 31-item questionnaire was adapted from the 61-item self-regulation questionnaire (Brown, Miller, \& Lawendowski, 1999). Carey and her colleagues (2004) found that a single factor solution was the easiest to interpret, with cross-loadings in various competing multidimensional structures leading to challenges regarding a valid factor structure. In the current study, the SSRQ is scored on a Likert scale ranging from 1 (strongly disagree) to 5 (strongly agree). An example of an item from the SSRQ is 'I set goals for myself and keep track of my progress'.

\section{Research procedure and ethical considerations}

Full ethical clearance and gatekeeper permission were obtained from the Research Ethics Committees of the four South African Universities that were selected for this study. Arrangements were made with the various human resources departments of each higher education institution to identify a list of women leaders who met the criteria set out in the current study, that is, females in leadership positions across the professional services (support) and academic occupational levels. These four universities assisted the primary researcher to send out the survey link to participants, which contained the link to the online questionnaire, the information leaflet and the letter of informed consent. Using the information leaflet, participants were informed on aspects relating to the purpose of the study, the possible benefits of the research and their rights as participants. The information leaflet indicated that the data collected would be stored in a password-protected database with only the researcher having access to the raw data. Participants were informed that participation in the study was on a voluntary basis and that they were free to withdraw from the study at any time should they feel the need to. The names and contact details of the researchers were also made available to the respondents.

\section{Statistical analysis}

A two-step process was followed in analysing the results of the present study. Firstly, for each of the four constructs, a unidimensional model with items loading directly onto the $a$ priori factor was evaluated using confirmatory factor analysis (CFA). Mplus (Muthén \& Muthén, 1998-2017) was employed to obtain relevant goodness-of-fit statistics. The following recommended values would be indicative of acceptable fit: root mean square error of approximation (RMSEA) $\leq 0.06$; standardised root mean squared residual (SRMR) $\leq 0.08$; comparative fit index $(\mathrm{CFI}) \geq 0.95$, Tucker-Lewis index (TLI) $\geq$ 0.95 (Hu \& Bentler, 1998, 1999; Steiger, 1990). The Robust Maximum-Likelihood method of estimation was used to obtain robust estimates for the parameters (e.g. factor loadings). In addition to CFA, descriptive statistics and Cronbach's alpha were calculated to summarise the basic features of the data and determine the reliability of the scales used.

Once the measurement quality of the instruments was determined, the researchers evaluated the various hypotheses related to mediation. Hayes' (2018) PROCESS macro (Model 6) for Statistical Package for the Social Sciences (SPSS) was used to conduct the analyses.

\section{Ethical considerations}

This study has received ethical clearance from the Research and Ethics Committee at the Faculty of Economic and Management Sciences, University of the Free State, reference number: UFS-HSD2017/0035.

\section{Results \\ Factor loadings and goodness of fit}

Although the primary focus of the present study was to test a serial-mediation model, a brief overview of the measurement qualities associated with the four constructs is warranted. All the items had significant factor loadings on their respective $a$ priori unidimensional factor. More specifically, factor loadings ranged between 0.424 and 0.826 for positive affect, between 0.373 and 0.733 for resilience, between 0.396 and 0.784 for general self-efficacy and between 0.294 and 0.751 for selfregulation. The following section reports the goodness of fit statistics associated with the four constructs.

Depending on the choice of fit index and its associated criteria, the goodness of fit associated with the four constructs can either be interpreted as good or poor. From Table 1, it is evident that all four instruments have good levels of fit, when considering that the values of the SRMR were lower than the recommended value $(\leq 0.08)$ (Hu \& Bentler, 1999). Except for the construct positive affect, the values associated with the RMSEA were slightly above the recommended value $(\leq 0.06)$, indicating poor fit. Finally, in terms of the CFI and TLI, both positive affect and self-efficacy have good fit, with values close to or slightly below the recommended value $(\geq 0.95)$ (Hu \& Bentler, 1999). 
TABLE 1: Goodness-of-fit statistics.

\begin{tabular}{lcccc}
\hline Variable & Positive affect & Resilience & Self-efficacy & Self-regulation \\
\hline S-B $\chi^{2}$ & 63.672 & 203.298 & 81.265 & 974.774 \\
$p$ & 0.002 & 0.000 & 0.000 & 0.000 \\
$d f$ & 35 & 77 & 35 & 434 \\
RMSEA & 0.057 & 0.080 & 0.072 & 0.070 \\
SRMR & $(0.034 ; 0.079)$ & $(0.067 ; 0.094)$ & $(0.052 ; 0.093)$ & $(0.064 ; 0.076)$ \\
CFI & 0.046 & 0.060 & 0.042 & 0.066 \\
TLI & 0.953 & 0.878 & 0.942 & 0.775 \\
\hline
\end{tabular}

RMSEA, root mean square error of approximation; SRMR, standardised root mean squared residual; CFI, comparative fit index; TLI, Tucker-Lewis index.

\section{Common method bias}

Common method bias was investigated at both the item and factor level. At the item levels, the results from Harmon's single factor test (Podsakoff \& Organ, 1986) were consulted. This approach employs exploratory factor analysis, constraining the solution to extract a single factor. The SPSS version 27 was used to conduct the exploratory factor analysis. As a guideline, the first factor should not explain more than $50 \%$ of the variance. Based on the results of the exploratory factor analysis, the first factor explained $24.7 \%$ of the variance. This seems to suggest that common method variance is not present. At the factor level, partial least squares structural equation modelling was used to obtain the relevant collinearity statistics - more specifically, the inner variance inflation factors (VIFs). Common method bias would be present (at the factor-level), if the inner VIF values are higher than 3.3 (Kock, 2015). SmartPLS (Ringle, Wende, \& Becker, 2015) was used to obtain these values. From Table 2 it is evident that VIFs from the full collinearity test are lower than the recommended guideline. Hence, at the factor-level, there is no evidence of common method bias.

\section{Descriptive statistics and reliability co-coefficients and correlations}

Table 3 presents the descriptive statistics, Cronbach's alpha and correlation coefficients for the variables under study. As indicated by the mean score, respondents in the current study possess a moderately high level of resilience. Similarly, results indicate that participants in the current sample reported moderately high levels of self-efficacy, positive affect and self-regulation. The reliability coefficient for each scale was assessed using Cronbach's Alpha coefficient and all scales indicated a Cronbach's alpha level of above 0.80, suggesting acceptable levels of internal consistency. As expected, all independent variables (positive affect, selfefficacy and self-regulation) shared a positive correlation with resilience. Additionally, all independent variables shared positive correlations with each other. All correlations were significant at the 0.01 level.

\section{Assessing indirect relationships between variables}

According to Preacher and Hayes (2008), the assessment of serial mediation models involves analysing the total, direct and all specific indirect effects. As a result, the indirect effects proposed in this study were assessed using the PROCESS
TABLE 2: Inner variance inflation factor values.

\begin{tabular}{lcccc}
\hline Variable & Positive effect & Resilience & Self-efficacy & Self-regulation \\
\hline Positive affect & - & 1.41 & 1.53 & 1.42 \\
Resilience & 1.46 & - & 1.55 & 1.48 \\
Self-efficacy & 1.47 & 1.45 & & 1.31 \\
Self-regulation & 1.66 & 1.66 & 1.58 & - \\
\hline
\end{tabular}

TABLE 3: Descriptive statistics and reliabilities and correlations $(n=255)$.

\begin{tabular}{|c|c|c|c|c|c|c|c|c|c|}
\hline Variable & $n$ & Min & Max & M & s.d. & $\alpha$ & 1 & 2 & 3 \\
\hline 1. Resilience & 255 & 3.57 & 7.00 & 5.97 & 0.64731 & 0.88 & - & - & - \\
\hline $\begin{array}{l}\text { 2. Positive } \\
\text { affect }\end{array}$ & 255 & 2.50 & 5.00 & 4.05 & 0.52131 & 0.85 & $0.507 * *$ & - & - \\
\hline 3. Self-efficacy & 255 & 2.00 & 4.00 & 3.39 & 0.37272 & 0.86 & $0.439 * *$ & $0.404 * *$ & - \\
\hline $\begin{array}{l}\text { 4. Self- } \\
\text { regulation }\end{array}$ & 255 & 2.48 & 5.00 & 4.05 & 0.44057 & 0.93 & $0.532 * *$ & $0.520 * *$ & $0.537 * *$ \\
\hline
\end{tabular}

Note: ${ }^{* *}, p<0.01$.

Min, minimum; Max, maximum; M, mean; s.d., standard deviation; $\alpha$, Cronbach's alpha.

macro for Model 6. According to Hayes (2018), this model is used when a serial multiple mediation model is proposed, that is, a model in which the independent variable $(X)$ has both direct and indirect effects on the dependant variable $(Y)$ and there are two or more mediators, with one of the mediators (M1) being a cause of the other mediator (M2). Model 6 allows the researcher to control the indirect effect of individual mediators, whilst controlling other variables.

In the current study, the independent variable was positive affect $(X)$; the dependent variable was resilience $(Y)$, whilst mediator 1 was self-efficacy (M1) and mediator two was selfregulation (M2). To run the mediation model, bootstrapping with bias-corrected confidence estimates was used. A 95\% confidence interval (CI) of the indirect effects was obtained by using 10000 bootstrap samples. The $95 \%$ confidence levels indicate that an indirect effect is significant (at alpha $=0.05$ ) and meaningful if zero does not fall within its $95 \%$ confidence interval.

From Figure 1, it is evident that there is a significant positive relationship between positive affect and resilience $\left(c^{\prime}=0.36 ; 95 \%\right.$ BCa CI [0.21-0.50]), providing support for Hypothesis 1. Thus, positive affect has a positive association with resilience independent of the indirect effects through self-efficacy and self-regulation. It should be noted that Figure 1 reports the ordinary least squares (OLS) regression outputs obtained from the PROCESS macro and do not report the evidence related to mediation (which is shared next).

In an attempt to test Hypotheses 2-4 proposed in this study, the total, direct and indirect effects of positive affect $(X)$ on resilience $(\mathrm{Y})$ were examined. The total effect of positive affect on resilience is significant $(c=0.63 ; 95 \%$ BCa CI [0.49-0.76]).

As seen in Table 4, the total indirect effect is significant and differs from zero (effect $=0.27 ; 95 \%$ BCa CI [0.17-0.39]) . When examining each of the specific proposed indirect effects, results indicated that the indirect effect of positive affect on resilience through self-efficacy was significant $($ effect $=0.08 ; 95 \%$ BCa CI $[0.01,0.16])$. This implies that 


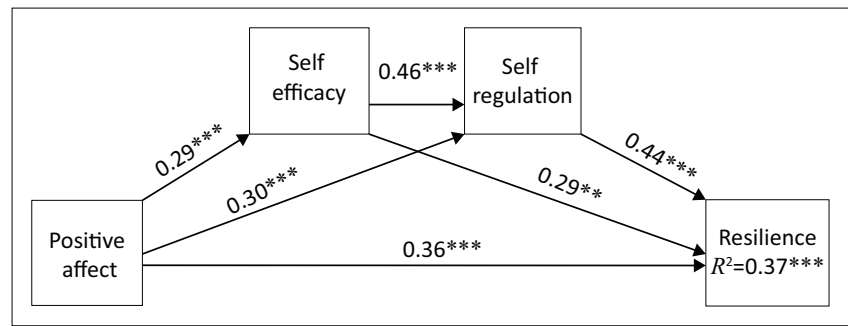

Note: $* *, p<0.01 ; * * *, p<0.001$.

FIGURE 1: Serial mediation model for positive affect, self-efficacy, self-regulation and resilience.

TABLE 4: Indirect effects of positive affect, self-efficacy and self-regulation on resilience.

\begin{tabular}{lcc}
\hline Indirect relationship & Effect & Cl \\
\hline Total indirect effects & 0.27 & $0.17,0.39$ \\
$\begin{array}{l}\text { Positive affect } \rightarrow \text { Self-efficacy } \rightarrow \text { Resilience } \\
\text { Ind 1) }\end{array}$ & 0.08 & $0.01,0.16$ \\
$\begin{array}{l}\text { Positive affect } \rightarrow \text { Self-regulation } \rightarrow \text { Resilience } \\
\text { Ind 2) }\end{array}$ & 0.13 & $0.07,0.21$ \\
$\begin{array}{l}\text { Positive affect } \rightarrow \text { Self-efficacy } \rightarrow \text { Self- } \\
\text { regulation } \rightarrow \text { Resilience (Ind 3) }\end{array}$ & 0.06 & $0.03,0.09$ \\
\hline
\end{tabular}

$\mathrm{Cl}$, confidence interval; Ind, indirect relationship.

those who reported more positive affect also reported more self-efficacy. This increase in self-efficacy is also associated with an increase in resilience. As a result, Hypothesis 2 (self-efficacy mediates the relationship between positive affect and resilience) was supported. Results of the indirect effects also indicated that the effect of positive affect on resilience through self-regulation was also significant (effect $=0.13 ; 95 \%$ BCa CI $[0.07,0.21]$ ). Put differently, those who reported more positive affect, also reported more self-regulation. This increase in selfregulation is also associated with an increase in resilience. As a result, Hypothesis 3 (self-regulation mediates the relationship between positive affect and resilience) was also supported. Finally, the serial multiple mediation of self-efficacy and self-regulation in the relationship between positive affect and resilience was also found to be significant (effect $=0.06 ; 95 \%$ BCa CI [0.03, 0.09]), leading to the support of Hypothesis 4 (there is a serial mediation effect of self-efficacy and self-regulation in the relationship between positive affect and resilience). This implies that those who reported more positive affect, also felt more confident and in turn were better able to regulate their behaviour. The ability to regulate oneself better in turn is also associated with more resilience.

The present study also investigated whether one indirect effect differs significantly from another indirect effect (see Table 5). Again, the PROCESS macro for Model 6 was used, but now requesting the pairwise contrasts of indirect effects (Hayes, 2018).

The first comparison asks the following question: is the specific indirect effect of positive affect on resilience through self-efficacy different from the specific indirect effect of positive affect on resilience through self-regulation? Based on the results shown in Table 5 , there is no difference (effect $=$ $-0.049 ; 95 \%$ BCa CI $[-0.16,0.07])$. This means that self-efficacy
TABLE 5: Pairwise comparisons between specific indirect effects.

\begin{tabular}{lcc}
\hline Variable & Effect & $\mathrm{Cl}$ \\
\hline Comparison 1: Ind 1 minus Ind 2 & -0.049 & $-0.16,0.07$ \\
Comparison 2: Ind 1 minus Ind 3 & 0.03 & $-0.06,0.11$ \\
Comparison 3: Ind 2 minus Ind 3 & 0.07 & $0.02,0.14$ \\
\hline
\end{tabular}

$\mathrm{Cl}$, confidence interval; Ind, indirect relationship.

(as a mechanism) does not account for more of the effect of positive affect on resilience than self-regulation (as a mechanism).

The second comparison asks the following question: is the specific indirect effect of positive affect on resilience through self-efficacy different from the specific indirect effect of positive affect on resilience through self-efficacy and selfregulation (in serial)? Based on the results in Table 5, there is no difference (effect $=0.03 ; 95 \%$ BCa CI $[-0.06,0.11]$ ). Put differently, self-efficacy (as a mechanism) does not account for more of the effect of positive affect on resilience than both self-efficacy and self-regulation (in serial).

The third, and final comparison asks the following question: is the specific indirect effect of positive affect on resilience through self-regulation different from the indirect effect of positive affect on resilience through self-efficacy and selfregulation (in serial)? Based on the results in Table 5 , there is indeed a difference (effect $=0.07 ; 95 \% \mathrm{BCa}$ CI $[0.02,0.14])$. This means that self-regulation (as a mechanism) accounts for more of the effect of positive affect on resilience than both self-efficacy and self-regulation (in serial).

\section{Discussion}

Studies on female leadership have indicated that equipping female leaders with the necessary resources to resist disruptions that threaten their career journeys is paramount in reducing the underrepresentation of females in leadership positions. Hence, resilience is a critical resource that can assist female leaders to successfully deal with barriers in the workplace allowing them to bounce back from setbacks. Several authors have argued that there are psychological strengths such as self-efficacy and self-regulation that can be used to explain the process of resilience and that exploring these strengths and the processes between them can assist researchers and organisations in promoting resilience amongst female leaders. The current study focused on assessing the proposed hypotheses which aimed to investigate the direct and indirect effects between positive affect, self-efficacy, self-regulation and resilience.

Results of the statistical analysis confirmed that positive affect was significantly associated with levels of resilience and this relationship was independent of the indirect relationships hypothesised in this study. These findings are consistent with Sagone and Indiana (2017) who reported that in their study that positive affect was positively related with high resilience. The authors also reported positive significant relationships between positive affect and aspects of resilience such as adaptability, sense of humour, control and engagement. 
Similarly, in their analysis of positive emotional states on resilience, Fredrickson, Tugade, Waugh and Larkin (2003) reported that positive emotions such as confidence, happiness and hope have been proven to significantly influence levels of resilience. According to the broaden-and-build theory of positive emotions (Fredrickson, 2003), experiencing a positive mood state elicits responses that are likely to facilitate resilience. Fredrickson (2003) argues that positive mood or affect broadens the mindset from a problem-focused approach to an approach that is solution-oriented. As a result, individuals who maintain a positive affect are generally able to deal with setbacks as they focus on solutions rather than problems. This allows them to remain resilient during stressful periods. Whilst it can be argued that maintaining a positive affect during adversity is rare, the consequence of the broadened mindset brought about by positive affect results in the discovery of new and innovative actions. These actions strengthen an individual's personal resources, which are then drawn upon when dealing with setbacks. This is primarily because the individual resources accumulated during experiences of positive emotions are long-lasting, that is, they carry on long after the transient emotional states that led to their acquisition end (Fredrickson, 2003). This explains why female leaders who display a positive affect are more likely to be resilient as they possess a wider range of resources to assist them in dealing with setbacks.

Once the direct relationship between positive affect and resilience was confirmed, the researchers aimed to investigate how positive affect explains resilience through three indirect explanatory mechanisms, that is, self-efficacy, self-regulation and the serial mediation of self-efficacy and self-regulation. In order to assess these explanatory mechanisms, a two-step process was adopted. In the first step, attempts were made to assess whether there is a mediation effect of self-efficacy, self-regulation and the serial mediation of self-efficacy and self-regulation in the relationship between positive affect and resilience. In step two, attempts were made to compare each indirect effect to determine if there were any significant differences between them

Based on the results of the mediation analysis, the relationship between positive affect and resilience was mediated by selfefficacy. Importantly, the results of the indirect effect indicated that the relationship between positive affect and resilience remained significant. This suggests that positive affect has a positive association with resilience independent of the indirect effect through self-efficacy. According to Sabouripour, Roslan, Ghiami and Memon (2021), the role of self-efficacy as a mediator in the relationship between positive affect and resilience lies in the notion of self-belief. A female leader's belief in her ability to successfully overcome barriers in the workplace has a significant effect on whether she is able to adjust to difficulties in the work environment, that is, resilience. This self-belief comes from maintaining a positive affect as it is the positive disposition that boosts selfconfidence, which encourages positive beliefs in one's abilities. Positive self-beliefs increase the likelihood of female leaders overcoming barriers in the workplace, which ultimately explains whether they are resilient. As a result, a positive affect explains whether the female leader has positive beliefs regarding her ability to overcome barriers in the workplace and this positive belief explains whether she is resilient. Self-efficacy may serve as an explanatory mechanism in the relationship between positive affect and resilience by accounting for the concept of self-belief.

The present study also found that self-regulation mediated the relationship between positive affect and resilience. However, it should be noted that the relationship between positive affect and resilience remained significant. This suggests that positive affect has a positive association with resilience independent of the indirect effect through selfregulation. Whilst maintaining a positive affect has been known to lead to broadened thought action repertoires, which facilitates positive response to setbacks, that is, resilience, Aspinwall (1998) argues that these broadened thoughts and actions can also facilitate self-regulatory processes which then go on to explain why some people are better able to regulate their behavioural responses and positively deal with threat, that is, resilience. Authors in the field of self-regulation argue that self-regulation as an explanatory mechanism in the relationship between positive affect and resilience can be explained by the role affect on judgement. When people who display a positive affect make judgments about situations, these judgments tend to be more flexible and creative than judgments made by people in negative or neutral moods. As a result, these creative judgments facilitate the active regulation of emotions, behaviours and thoughts in creative ways, that is, selfregulation. The positive regulation of emotions, behaviours and thoughts allows the individual to adapt to threating situations and bounce back after setbacks, that is, resilience.

The final indirect effect focused on the relationship between positive affect, self-efficacy, self-regulation and resilience using a serial mediation model. With this model, it was assumed that positive affect is associated with resilience but that both self-efficacy and self-regulation would mediate the relationship between positive affect and resilience with a causal linkage between the two mediators. Results of the statistical analysis confirmed the serial mediation of selfefficacy and self-regulation in the relationship between positive affect and resilience. The relationship between positive affect and resilience remained significant when selfefficacy and self-regulation (in serial) were controlled. This suggests that positive affect has a positive association with resilience independent of the indirect serial effect through self-efficacy and regulation. The significant result provides a reason to believe that positive affect explains self-efficacy, which explains self-regulation, and these mechanisms go on to explain levels of resilience. In a study conducted by Totawar and Nambudiri (2014), the authors argued that positive affect or mood is associated with levels of selfefficacy as it increases self-beliefs and promotes positive beliefs about one's abilities to overcome barriers in the work environment (i.e. people feel more capable and efficient when they are in a good mood or maintain a positive affect). 
The positive belief (self-efficacy) that one has in one's abilities goes on to promote positive regulation of thoughts and behaviour explaining why some people are able to remain resilient during unfavourable conditions. In their study, Bouchard, Parent and Larivee (1991) concluded that selfefficacy wielded substantial influence on several aspects of self-regulation including task persistence. The link between self-efficacy and self-regulation found in the sample of women leaders in this study is also consistent with the study by Klassen (2010) who concluded that the link between selfefficacy and self-regulation could be understood through how self-efficacy leads to regulatory behaviour. The author argued that positive self-efficacy beliefs that are a result of positive affect increase one's level of control over the belief that they can overcome challenges and obstacles in the workplace. This belief goes on to motivate individuals to regulate their behaviour, emotion and thoughts accordingly, which leads to more adaptive ways of dealing with setbacks, which results in greater resilience.

In the second step of the mediation analyses, attempts were made to compare the three indirect effects to determine whether there were significant differences in the explanatory mechanisms of self-efficacy, self-regulation and the serial link of self-efficacy and self-regulation in the relationship between positive affect and resilience. Results indicated that the indirect effect of positive affect on resilience through selfregulation is significantly different from the indirect effect of positive affect on resilience through self-efficacy and selfregulation (in serial) indicating that self-regulation (as a mechanism) provides a stronger explanation for the association between positive affect and resilience than both self-efficacy and self-regulation (in serial). A possible reason for the effectiveness of self-regulation as an explanatory mechanism in the positive affect-resilience relationship could lie in different processes through which emotion affects behaviour. Baumeister, DeWall, Vohs and Alquist (2010) argue that there are two primary processes through which emotions translate into behaviour. In the first process, emotion can be described as a conscious state of feeling, which is characterised by a bodily response, such as physiological arousal. In most cases, the individual tends to experience one emotion at a time and these emotional states are slow to arise and slow to dissipate. The link between these emotional states and behaviour, in most cases, occurs through cognitive processes (i.e. individuals consciously experience an emotion which informs how they cognitively process an event which informs their behaviour). The second and most common process in which emotion may explain behaviour is through automatic affect. Baumeister et al. (2010) argue that this process occurs unconsciously as affect is usually an enduring mood state that the individual maintains across a range of situations. Process one (i.e. conscious emotion), typically, involves a bodily response, including arousal that can take some time to develop, and as a result may not be effective for providing input into behavioural decisions in a fast-changing or newly emerging situation. In contrast, process two (i.e. automatic affect) arises within milliseconds and occurs fast enough to contribute to quick reactions. Within the current study, the process between emotion and behaviour was framed in line with process two in which affect is automatic, that is, positive affect is an enduring mood state, and leads to automatic behavioural responses (self-regulation). Baumeister et al. (2010) argue that in process two in which emotion is described as an automatic affective state, emotion is independent of cognition. The authors state that when affect is used, the individual is able to decide whether an event is favourable or unfavourable almost immediately after encountering the event and based on that feeling, the individual reacts accordingly. Therefore, very little cognitive processing is required beyond knowing whether something is favourable or unfavourable and perhaps having one simple association. It has been suggested that self-regulation strategies can be used to either influence the intensity and/or the duration of an emotional state (Larsen \& Prizmic, 2004). It is therefore likely that individuals can use self-regulation to maintain a positive mood for much longer (even in the face of adversity) to increase their resilience. Hence, self-regulation may assist in allowing individuals to use positive affect (as a resource) to enhance their levels of resilience. This could explain why the process of positive affect (emotion) to self-regulation (behaviour) was a better explanatory mechanism for resilience than positive affect (emotion) to self-efficacy (cognition) to self-regulation (behaviour) to resilience in the current study.

Although not directly related to the purpose of the present study, it could be of interest to answer the following question (stemming from the results associated with comparing each indirect effect to determine if there were any significant differences between them): why would there be no significant difference between the indirect effect through self-efficacy and the indirect effect though self-regulation? Self-regulation refers to 'self-generated thoughts, feelings and actions that are planned and cyclically adapted to the attainment of personal goals' (Zimmermann, 2005, p. 14). In contrast, selfefficacy relates to individuals' beliefs about their ability to successfully perform certain tasks and achieve the goals they have set (Bandura, 1997). According to Zimmerman (2005), self-regulation consists of three phases: forethought (when goals are set and strategies are planned and selected), performance (the implementation of strategies selected/ planned during the forethought phase) and self-reflection (motivation and emotion). According to Zimmerman's selfregulation model (2005), self-efficacy is viewed as a motivational component of forethought, influencing the choice of strategies selected and implemented to attain personal goals. It therefore seems likely that because selfefficacy is a motivational component of self-regulation, it is 'part of' self-regulation and can be incorporated in an individual's self-regulatory behaviours and thoughts - hence no difference in the effect between self-regulation and selfefficacy.

From the arguments made above, it can be concluded that whilst all three indirect effects explored in the current study were found to be significant, self-regulation was a better 
explanatory mechanism than the serial effect of self-efficacy and self-regulation in the relationship between positive affect and resilience.

\section{Practical implications}

Female leaders in the 21st century are dealing with volatile, uncertain, complex and ambiguous work environments. In addition to volatile nature of the South African higher education environment and the gender-specific barriers, women leaders in South African higher education institutions must also deal with the COVID-19 pandemic, which has added an extra element of uncertainty to the leadership context. This has made resilience an invaluable resource for female leaders in the workplace. Whilst the role of employees' wellness programmes has increased significantly during the global pandemic, very few of these initiatives prioritise resilience development for female leaders and even less focus on cultivating psychological strengths such as positive affect, self-efficacy and self-regulation as tools for female leadership during the global crises. Results of the current study indicate that positive affect, self-efficacy and self-regulation can serve as useful psychological resources that may be used mechanisms to facilitate resilience for female leaders.

According to Armenta, Fritz and Lyubomirsky (2017), positive affect can be facilitated through the simple act of expressing gratitude. In terms of female leadership development, this can be facilitated through development programmes that emphasise an appreciative enquiry approach (Wall, Russel, \& Moore, 2017). Rogers and Fraser (2003) state that appreciative inquiry methods are based on the premise that highlighting the positive aspects and experiences can encourage positive affect. This approach is based on one of the three pillars of positive psychology, that is, positive experiences, and assumes that emphasising positive experiences will increase positive affect (Lambert et al., 2013). Facilitators of female leadership development programmes can incorporate the appreciative enquiry approaches for female leaders through leadership coaching sessions. Coaches and mentors can work with female leaders to encourage focus on positive aspects of leadership and the progress made in their career journeys.

Based on the positive relationship between positive affect and self-efficacy found in this study, it can be argued that attempts made to increase self-efficacy should first look at increasing positive affect. Additionally, self-efficacy can be enhanced through four specific ways, which include mastery experience, vicarious experience, verbal persuasion and emotional states. Joët, Bressoux and Usher (2011) state that of these sources, the most effective source of self-efficacy usually comes from one's perceptions of one's own performance, or mastery experience. This is because when people perceive themselves as being successful in varying tasks, their belief in their abilities begins to increase. Higher education institutions can facilitate mastery experience for female leaders by promoting work challenges and opportunities to learn new skills. This can be carried out by using the existing in-house leadership development programmes and including opportunities to develop advanced leadership skills and providing opportunities to work through tasks related to problem-solving ability, systems thinking and emotional intelligence.

Finally, the results of the study confirmed the invaluable role of self-regulation in mediating the relationship between positive affect and resilience. Results suggest that higher education institutions should prioritise self-regulation as a mediating mechanism between positive affect and resilience. By facilitating and enhancing positive affect and self-efficacy, leadership development programmes can also encourage self-regulatory behaviours amongst female leaders, which is associated with resilience. Johnson (2017) advises that because self-regulation refers to the capacity to develop, exercise and flexibly manage planned behaviour in order to achieve one's goals, higher education institutions can utilise coaches and mentors in the context of personal development sessions to set career goals. These coaches and mentors can also assist female leaders with regulating their thoughts, behaviours and emotions when these career goals do not go as planned.

\section{Limitations}

Although the measures used in the current study were considered adequate to measure each construct, the use of self-report scales is likely to lead to the subjective interpretations by the female leaders, which could have led to method bias and may have produced inflated correlations between the study variables. As a result, the researchers ran the necessary statistical tests for common method bias and results reveal that there was no method bias. In addition, it must be noted that the correlations reported in the current study were in line with previous published findings, which suggests that the impact of participant's subjectivity on the overall findings is low.

Secondly, it must be noted that the current sample consisted of highly educated female leaders who possessed many years of experience in leadership roles. These factors could possibly serve as a boundary condition for the applicability of the results to other education groups. Whilst most published studies (Bonanno, Galea, Bucciarelli, \& Vlahov, 2007) have reported inconsistent findings regarding differences in the variables under study in terms of education and experience levels, the impact on generalisability of the findings must be noted.

Finally, whilst the current study chose to adopt a micro-level approach, there are a significant number of studies that advocate for a socio-ecological approach to resilience, which considers the macro-level influences on resilience. Given that the focus of the current study was to explore the explanatory mechanisms through which individual psychological resources explain resilience, the use of a micro-level approach was justified in the current study. However, future studies are encouraged to adopt a multi-level perspective, that is, 
micro- and macro-level approach when investigating resilience.

\section{Conclusion}

Overall, the results of this study provide evidence of the importance of positive affect, self-efficacy and self-regulation in predicting levels of resilience. As a result, organisations that intend to increase levels of resilience amongst female leaders must focus on increasing positive affect, self-efficacy and most importantly, self-regulation as these variables were found to facilitate resilience. As indicated by the indirect effects found in the current study, organisations should focus on using these psychological resources individually and in combination with each other.

\section{Acknowledgements Competing interests}

The authors declare that they have no financial or personal relationships that may have inappropriately influenced them in writing this article.

\section{Author's contributions}

D.P. conceptualised, collected data, conducted data analysis and wrote the first draft of this article. P.N. validated the research findings, and assisted in the editing and supervision of the larger research project. E.v.Z. assisted in editing and supervision of the larger research project.

\section{Funding information}

This research received no specific grant from any funding agency in the public, commercial or not-for-profit sectors.

\section{Data availability}

Data sharing is not applicable to this article as no new data were created or analysed in this study.

\section{Disclaimer}

The views and opinions expressed in this article are those of the authors and do not necessarily reflect the official policy or position of any affiliated agency of the authors.

\section{References}

Akthar, M. (2008, November 8). What is self-efficacy? Bandura's 4 sources of efficacy beliefs. Positive Psychology. Retrieved from http://positivepsychology.org.uk/selfefficacy-definition-bandura-meaning/

Armenta, C.N., Fritz, M.M., \& Lyubomirsky, S. (2017). Functions of positive emotions: Gratitude as a motivator of self-improvement and positive change. Emotion Review, 9(3), 183-190. https://doi.org/10.1177/1754073916669596

Aspinwall, L.G. (1998). Rethinking the role of positive affect in self-regulation. Motivation and Emotion, 22(1), 1-32. https://doi.org/10.1023/A:102308 0224401

Bandura, A. (1982). Self-efficacy mechanism in human agency. American Psychologist, 37(2), 122. https://doi.org/10.1037/0003-066X.37.2.122

Bandura, A. (1991). Social cognitive theory of self-regulation. Organizational Behavior and Human Decision Processes, 50(2), 248-287. https://doi.org/10.1016/07495978(91)90022-L

Bandura, A. (1994). Self-efficacy. In V.S. Ramachaudran (Ed.), Encyclopedia of human behavior (vol. 4, no. 4, pp. 71-81). New York: Academic Press.
Bandura, A. (1997). Self-efficacy: The exercise of control. New York, NY: Freeman.

Baumeister, R.F., DeWall, C.N., Vohs, K.D., \& Alquist, J.L. (2010). Does emotion cause behavior (apart from making people do stupid, destructive things). In: C. Agnew, C. Carlston, D. Graziano, \& J. Kelly (Eds.), Then a Miracle Occurs: Focusing on Behavior in Social Psychological Theory (pp. 12-27). New York: Oxford University Press.

Bonanno, G.A., Galea, S., Bucciarelli, A., \& Vlahov, D. (2007). What predicts psychological resilience after disaster? The role of demographics, resources, and life stress. Journal of Consulting and Clinical Psychology, 75(5), 671. https://doi. org/10.1037/0022-006X.75.5.671

Brown, J.M., Miller, W.R., \& Lawendowski, L.A. (1999). The self-regulation questionnaire. In L. VandeCreek, \& T.L. Jackson (Eds.), Innovations in clinical practice: A sourcebook (pp. 281-292). Sarasota, FA: Professional Resource Press/ Professional Resource Exchange.

Carey, K.B., Neal, D.J., \& Collins, S.E. (2004). A psychometric analysis of the selfregulation questionnaire. Addictive Behaviours, 29(2), 253-260. https://doi. org/10.1016/j.addbeh.2003.08.001

Charalambous, A., Giannakopoulou, M., Bozas, E., \& Paikousis, L. (2019). Parallel and serial mediation analysis between pain, anxiety, depression, fatigue and nausea, vomiting and retching within a randomised controlled trial in patients with breast vomiting and retching within a randomised controlled trial in patients with breast
and prostate cancer. BMJ Open, 9(1), e026809. https://doi.org/10.1136/ and prostate cancer.
bmjopen-2018-026809

Cusack, L., Smith, M., Hegney, D., Rees, C.S., Breen, L.J., Witt, R.R., Rogers, C., Williams, A., Cross, W., \& Cheung, K. (2016). Exploring environmental factors in nursing workplaces that promote psychological resilience: Constructing a unified theoretical model. Frontiers in psychology, 7(600), 1-8. https://doi.org/10.3389/fpsyg.2016.00600

Duchek, S. (2018). Entrepreneurial resilience: A biographical analysis of successful entrepreneurs. International Entrepreneurship and Management Journal, 14(2), 429455. https://doi.org/10.1007/s11365-017-0467-2

Foerster, C., \& Duchek, S. (2017). What makes leaders resilient? An exploratory interview study. German Journal of Human Resource Management, 31(4), 281-306. https://doi.org/10.1177/2397002217709400

Forbes-Genade, K., \& Van Niekerk, D. (2019). GIRRL power! Participatory action research for building girl-led community resilience in South Africa. Action Research, 17(2), 237-257. https://doi.org/10.1177/1476750318756492

Fredrickson, B.L. (2001). The role of positive emotions in positive psychology: The broaden-and-build theory of positive emotions. American Psychologist, 56(3), 218. https://doi.org/10.1037/0003-066X.56.3.218

Fredrickson, B.L. (2003). The value of positive emotions: The emerging science of positive psychology is coming to understand why it's good to feel good. American Scientist, 91(4), 330-335. https://doi.org/10.1511/2003.4.330

Fredrickson, B.L. (2008). Promoting positive affect. In M. Eid \& R.J. Larsen (Eds.), The science of subjective well-being (pp. 449-468). New York, NY: Guilford Press.

Fredrickson, B.L., Tugade, M.M., Waugh, C.E., \& Larkin, G.R. (2003). What good are positive emotions in crisis? A prospective study of resilience and emotions following the terrorist attacks on the United States on September 11th, 2001. Journal of Personality and Social Psychology, 84(2), 365. https://doi. org/10.1037/0022-3514.84.2.365

Gray, D., \& Jones, K. (2018). The resilience and well-being of public sector leaders. International Journal of Public Leadership, 14(3), 138-154. https://doi. org/10.1108/IJPL-09-2017-0033

Haase, C.M., Poulin, M.J., \& Heckhausen, J. (2012). Happiness as a motivator: Positive affect predicts primary control striving for career and educational goals.

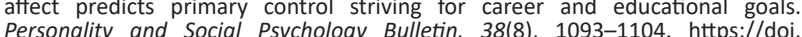
Personality and Social Psychology
org/10.1177/0146167212444906

Hannum, K.M., Muhly, S.M., Shockley-Zalabak, P.S., \& White, J.S. (2015). Women leaders within higher education in the United States: Supports, barriers, and experiences of being a senior leader. Advancing Women in Leadership Journal, 35, 65-75.

Hartmann, S., Weiss, M., Newman, A., \& Hoegl, M. (2020). Resilience in the workplace: A multilevel review and synthesis. Applied Psychology, 69(3), 913-959. https:// doi.org/10.1111/apps.12191

Hayes, A.F. (2018). Introduction to mediation, moderation, and conditional process analysis: A regression-based approach (2nd ed.). New York: Guilford Publications.

Hobfoll, S.E. (2002). Social and psychological resources and adaptation. Review of General Psychology, 6(4), 307-324. https://doi.org/10.1037/1089-2680.6.4.307

$\mathrm{Hu}$ L., \& Bentler, P.M. (1998). Fit indices in covariance structure modeling: Sensitivity to underparameterized model misspecification. Psychological Methods, 3(4), to underparameterized model misspecification. Psycho

$\mathrm{Hu}$, L., \& Bentler, P.M. (1999). Cutoff criteria for fit indexes in covariance structure analysis: Conventional criteria versus new alternatives. Structural Equation Modeling, 6(1), 1-55. https://doi.org/10.1080/10705519909540118

Joët, G., Usher, E.L., \& Bressoux, P. (2011). Sources of self-efficacy: An investigation of elementary school students in France. Journal of Educational Psychology, 103(3) 649. https://doi.org/10.1037/a0024048

Johnson, D.H. (2017). Maintenance of certification and Texas SB 1148: A threat to professional self-regulation. JAMA, 318(8), 697-698. https://doi.org/10.1001/ jama.2017.10127

Kele, T., \& Pietersen, J. (2015). Women leaders in a South African higher education institution: Narrations of their leadership operations. OIDA International Journal of Sustainable Development, 8(5), 11-16.

Klassen, R.M. (2010). Confidence to manage learning: The self-efficacy for self-regulated learning of early adolescents with learning disabilities. Learning Disability Quarterly, 33(1), 19-30. https://doi.org/10.1177/073194871003300102

Kock, N. (2015). Common method bias in PLS-SEM: A full collinearity assessment approach. International Journal of e-Collaboration (IJeC), 11(4), 1-10. https://doi. org/10.4018/ijec.2015100101 
Lambert, N.M., Gwinn, A.M., Baumeister, R.F., Strachman, A., Washburn, I.J., Gable, S.L., \& Fincham, F.D. (2013). A boost of positive affect: The perks of sharing positive experiences. Journal of Social and Personal Relationships, 30(1), 24-43. https://doi.org/10.1177/0265407512449400

Larsen, R.J., \& Prizmic, Z. (2014). Affect regulation. In R.F. Baumeister \& K.D. Vohs (Eds.), Handbook of self-regulation: Research, theory, and application (pp. 40-61). New York, NY: The Guilford Press.

Linden, P.R. (2012). Women and the organizational chess game: A qualitative study of gender, discourse, power, and strategy. Doctoral dissertation. Capella University: ProQuest.

Luszczynska, A., Scholz, U., \& Schwarzer, R. (2005). The general self-efficacy scale: Multicultural validation studies. The Journal of Psychology, 139(5), 439-457. https://doi.org/10.3200/JRLP.139.5.439-457

Manomenidis, G., Panagopoulou, E., \& Montgomery, A. (2019). Resilience in nursing: The role of internal and external factors. Journal of Nursing Management, 27(1) 172-178. https://doi.org/10.1111/jonm.12662

Marais, C.P. (1997). Salutogenesis as paradigm in change management. Master's dissertation, University of South Africa, Pretoria, South Africa. Pretoria: Unisa.

Marsh, H.W., \& Craven, R.G. (2006). Reciprocal effects of self-concept and performance from a multidimensional perspective: Beyond seductive pleasure and unidimensional perspectives. Perspectives on Psychological Science, 1(2), 133-136. https://doi.org/10.1111/j.1745-6916.2006.00010.x

Morley, L. (2013). The rules of the game: Women and the leaderist turn in higher education. Gender and Education, 25(1), 116-131. https://doi.org/10.1080/0954 0253.2012.740888

Muthén, L.K., \& Muthén, B.O. (1998-2011). Mplus user's guide (6th ed.) Los Angeles, CA: Muthén \& Muthén.

Park, I.J., Kim, M., Kwon, S., \& Lee, H.G. (2018). The relationships of self-esteem future time perspective, positive affect, social support, and career decision: $A$ longitudinal multilevel study. Frontiers in Psychology, 9, 514. https://doi. org/10.3389/fpsyg.2018.00514

Park, N., Peterson, C., \& Seligman, M.E. (2004). Reply: Strengths of character and wellbeing: A closer look at hope and modesty. Journal of Social and Clinical Psychology, 23(5), 603-619. https://doi.org/10.1521/jscp.23.5.628.50749

Pillay, D. (2020). Positive affect and mindfulness as predictors of resilience amongst women leaders in higher education institutions. SA Journal of Human Resource Management, 18(1), 1-10. https://doi.org/10.4102/sajhrm.v18i0.1260

Podsakoff, P.M., \& Organ, D.W. (1986). Self-reports in organizational research Problems and prospects. Journal of Management, 12(4), 531-544. https://doi org/10.1177/014920638601200408

Preacher, K.J., \& Hayes, A.F. (2008). Asymptotic and resampling strategies for assessing and comparing indirect effects in multiple mediator models. Behavior Research Methods, 4O(3), 879-891. https://doi.org/10.3758/BRM.40.3.879

Reed, D.E., \& Blaine, B. (2015). Resilient women educational leaders in turbulent times: Applying the Leader Resilience Profile ${ }^{\circledast}$ to assess women's leadership strengths. Planning and Changing, 46(3/4), 459.

Ringle, C.M., Wende, S., \& Becker, J.-M. (2015). SmartPLS 3. Bönningstedt: SmartPLS Retrieved from https://www.smartpls.com

Rogers, P.J., \& Fraser, D. (2003). Appreciating appreciative inquiry. New Directions for Evaluation, 2003(100), 75-83. https://doi.org/10.1002/ev.101

Ryan, R.M., \& Deci, E.L. (2001). On happiness and human potentials: A review of research on hedonic and eudaimonic well-being. Annual Review of Psychology, 52(1), 141-166. https://doi.org/10.1146/annurev.psych.52.1.141
Sabouripour, F., Roslan, S., Ghiami, Z., \& Memon, M.A. (2021). Mediating role of selfefficacy in the relationship between optimism, psychological well-being, and resilience among Iranian students. Frontiers in Psychology, 12, 675645. https:// resilience among Iranian students.
doi.org/10.3389/fpsyg.2021.675645

Sagone, E., \& Indiana, M.L. (2017). The relationship of positive affect with resilience and self-efficacy in life skills in Italian adolescents. Psychology, 8(13), 2226. https://doi.org/10.4236/psych.2017.813142

Schwarzer, R., \& Jerusalem, M. (1995). Generalized self-efficacy scale. Measures in health psychology: A user's portfolio. Causal and Control Beliefs, 1(1), 35-37. https://doi.org/10.1037/t00393-000

Southwick, F.S., Martini, B.L., Charney, D.S., \& Southwick, S.M. (2017). Leadership and resilience. In J. Marques, \& S. Dhiman (Eds.), Leadership today (pp. 315-333). Switzerland: Springer International Publishing.

Steiger, J.H. (1990). Structural model evaluation and modification: An interval estimation approach. Multivariate Behavioral Research, 25(2), 173-180. https:// doi.org/10.1207/s15327906mbr2502_4

Tau, B., Du Plessis, E., Koen, D., \& Ellis, S. (2018). The relationship between resilience and empowering leader behaviour of nurse managers in the mining healthcare sector. Curationis, 41(1), 1-10. https://doi.org/10.4102/curationis.v41i1.1775

Tice, D.M., Baumeister, R.F., Shmueli, D., \& Muraven, M. (2007). Restoring the self: Positive affect helps improve self-regulation following ego depletion. Journal of Experimental Social Psychology, 43(3), 379-384. https://doi.org/10.1016/j. jesp.2006.05.007

Totawar, A.K., \& Nambudiri, R. (2014). Mood and self-efficacy: The moderation of hedonic and utilitarian motivation. Human Resource Development Review, 13(3), 314-335. https://doi.org/10.1177/1534484313492330

Tugade, M.M., \& Fredrickson, B.L. (2004). Resilient individuals use positive emotions to bounce back from negative emotional experiences. Journal of Personality and Social Psychology, 86(2), 320. https://doi.org/10.1037/0022-3514.86.2.320

Tyng, C.M., Amin, H.U., Saad, M.N., \& Malik, A.S. (2017). The influences of emotion on learning and memory. Frontiers in Psychology, 8, 1454. https://doi.org/10.3389/ fpsyg.2017.01454

Van Niekerk, M.M. (2005). Transformational leadership at a higher education institution. Doctoral dissertation, University of South Africa, South Africa.

Wagnild, G., \& Young, H. (1993). Development and psychometric evaluation of the resilience scale. Journal of Nursing Measurement, 1(2), 165-178.

Wagnild, G., \& Young, H. (2009). A review of the resilience scale. Journal of Nursing Measurement, 17(2), 105-113. https://doi.org/10.1891/1061-3749.17.2.105

Wall, T., Russell, J., \& Moore, N. (2017). Positive emotion in workplace impact: The case of a work-based learning project utilising appreciative inquiry. Journal of Work-Applied Management, 9(2), 129-146. https://doi.org/10.1108/JWAM-07 2017-0017

Watson, D., \& Clark, L.A. (1992). Affects separable and inseparable: On the hierarchica arrangement of the negative affect. Journal of Personality and Social Psychology, 62(3), 489. https://doi.org/10.1037/0022-3514.62.3.489

Watson, D., Clark, L.A., \& Tellegen, A. (1988). Development and validation of brief measures of positive and negative affect: The PANAS scales. Journal of Personality and Social Psychology, 54(6), 1063. https://doi.org/10.1037//0022 3514.54.6.1063

Weatherspoon-Robinson, S. (2013). African American female leaders: Resilience and success. Pepperdine University. Malibu, CA: Pepperdine University.

Zimmerman, B.J. (2005). Attaining self-regulation: A social cognitive perspective. In M Boekaerts, P.R. Pintrich, \& M. Zeidner (Eds.), Handbook of self-regulation (2nd ed. pp. 13-39). San Diego, CA: Academic Press. 